\title{
المثلتقى العلمي
}

\section{تقرير الملتقى العلمي لقسم الصحافة}

إعداد/د. د. سماح الشهاوي"

شهد الملتقي العلمي لقسم الصحافة والأي عُقد في مايو 2016 مناقثــة ســـ خطط بحثية، تثمل خطة مقدمة للتسجيل لارجة الاكتور اه، وخمس خطط للتسجيل لارجة الماجستير، وذلك على النحو التالي: وجاءت الخطة المقدمة للتسجيل لارجة الاكتور اه على النحو التالي: - خطة مقدمة من الباحث أحمد سيد عبد العظيم بعنوان " آليات بناء أطر تقديم القضايا الاقتصادية في المواقع المتخصصة- دراسة للمحتوى وللقائم بالاتصال" تحت إشر اف أ.د أمل السيد.

تتمثل مشكلة الدر اسة في محاولة التعرف على آليات بناء أطر التغطية الصحفية للمو اقع الإكترونية المتخصصة للقضايا الاقتصادية، ودور القائم بالاتصال في هذا التأطير و انعكاسات هذا التأطير على مضمون هذه القضايا الاقتصادية في علاقته بما تقدمه و تطرحه المو اقع الإلكترونية من سمات وخصائص الثز اء و التقاعل. وتوظف الدر اسة نظرية تحليل الأطر الإعلامية، ونظرية اتخاذ القرارات، ونظرية ثر اء الوسيلة الإعلامية، وتتنمي هذه الدر اسة لنمط الدر اسات الوصفية وستعتمد الدراسة على منهج المسح الذي يستهدف الكثف عن مجموعة الآليات المؤثزة في بناء أطر تقديم القضايا الاقتصادية في المو اقع المتخصصة.

وتتمثل أدو ات الدر اسة في صحيفة الاستقصاء على القائم الاتصال في مجمو عة من المو اقع الاقتصادية المتخصصة بالإضافة إلى استمارة تحليل مضمون للقضايا المتعلقة بالتتمية الاقتصادية في الفترة من 4 يوليو 2014 وحتى نهاية 2016،

"الدرس بقسم الصحافة بكلية الإعلام - جامعة القاهرة 
بالإضافة إلى ذلك استمارة المقابلة المتعقة للقيادات التحريرية في المواقع الاقتصادية المتخصصة. أما عينة المو اقع التي ستخضع للار اسة فتتمثل في مو اقع المال و البورصة و أمو ال الغد و السوق العربية المشتركة.

وبالنسبة للخطط المقدمة للتسجيل لارجة الماجستير فجاءت على النحو التالي: - خطة مقدمة من الباحث محمد سعيد حسن بعنوان "تأثير الاختلافات الثقافية

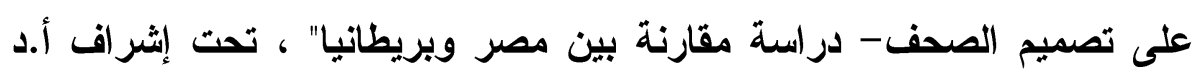

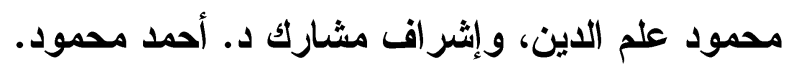

تتحدد مشكلة الدراسة في قياس أثر الاختلافات الثقافية على التصميم الصحفي وقياس أثر ثقافة المصمم على التصميم وذلك أثناء عملية التصميم ذاتها، وكذلك وضع إطار علمي يمكن من خلاله التأصيل لفكرة التصميم المبني على الثقافة و الذي تعد الثقافة فيه عاملا رئيسا يستمد من خلاله التصميم القدرة على التتوع و التحديث وذللك لتنوع و اختلاف البيئة الثقافية التي تصدر فيها الصحيفة. وتعتمد الدراسة في بنائها النظري على نظرية أبعاد القيم الثقافية ل "جبرت

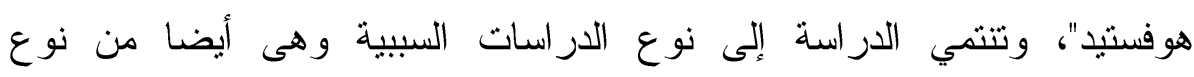
الدر اسات المشتركة بين الثقافات من حيث مقارنتها بين أثر ثقافة المجتمع المصري ولثي

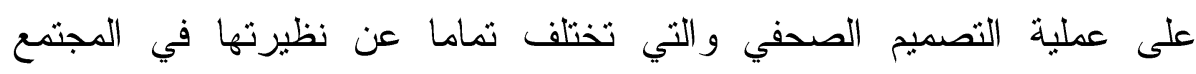
البريطاني، وتعتمد منهية الدر اسة على البروتوكول اللفظي وموجز التصميم. وتتمثل أدوات الدراسة في الملاحظة المتعمقة والمقابلات المتعقة، وتثمثل عينة الار اسة في صحف الأهر ام و الوفد و المصري اليوم أما عينة الصحف البريطانية

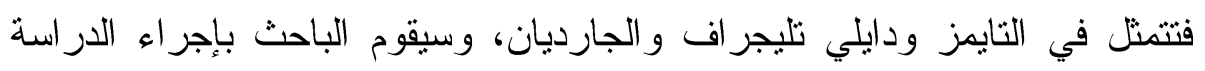
الميدانية على فريق التصميم في كل من صحف العينة. 
- خطة مقدمة من الباحثة شيماء محمود جابر بعنوان "العوامل المؤثرة على الخطاب التنموي في الصحافة المصرية تجاه الحقوق الاقتصادية والاجتماعية تجاه الحقوق الاقتصادية والاجتماعية- دراسة مسحية للمضمون و القائم بالاتصال"، تحت إثر اف أ.د نجوى كامل، و إثر اف مشارك د. إيمان حسني. تثمثل مشكلة الدراسة في التعرف على العو امل المؤثرة على الخطاب التتموي في الصحافة المصرية تجاه الحقوق الاقتصادية والاجتماعية من خلال رصد وتوصيف و تحليل وتفسير الخطاب الصحفي التتموي الاجتماعي و الاقتصادي بتحديد سمات و أدوار القوى الفاعلة المحركة في هذا الخطاب، وعرض الأدلة و البراهين التي

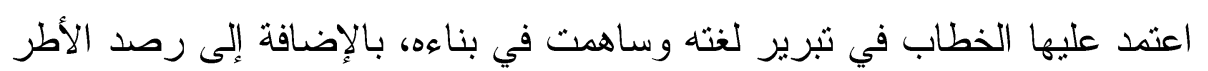
المرجعية التي استند إلبها ذلك الخطاب في طر ح وجهة نظره.

وتعتمد الدراسة في بنائها النظري على مدخل تحليل النظم ونظرية المسئولية الاجتماعية ونظرية حارس البوابة، وتتنمي الدراسة إلى حقل الدراسات الوصفية التحليلية، وتعنمد على منهج المسح و المنهج المقارن. أما أدوات الدراسة التي ستوظفها الباحثة فتتمثل في أسلوب تحليل القوى الفاعلة وتحليل مسارات البرهنة وأسلوب تحليل الأطر المرجعية، و المقابلة وصحيفة الاستقصاء. و تتمثل عينة الصحف التي ستخضع للار اسة في صحف الأهر ام و الوفد و المصري اليوم، أما الفنون الصحفية التي ستخضع للار اسة فتتمثل في مختلف الفنون الصحفية الخبرية و الاستقصائية و التقسيرية المرتبطة بموضو ع الدر اسة. - خطة مقدمة من الباحثة وفاء فايز عبد الرحمن بعنوان "العوامل المؤثرة على أطر تقديم قضايا التعليم الجامعي في الصحافة المصرية- دراسة للمضمون و القائم بالاتصال" تحت إثر اف أ.د نجوى كامل. 
تستهدف الار اسة رصد وتحليل الأطر التي تقدم من خلالها قضايا التعليم الجامعي

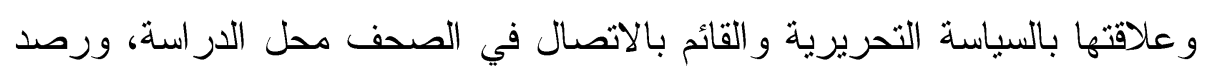
مكونات الخطاب الصحفي إزاء قضايا التعليم الجامعي، ومعرفة حجم اهتمام صحف الدراسة بقضايا التعليم الجامعي ومدى التزكيز على قضايا معينة و إغفال

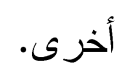

وتعتمد الدراسة في بنائها النظري على نظرية تحليل الإطار الإعلامي، وتتنمي الار اسة للار اسات الوصفية التحليلية وتوظف منهج المسح و المنهج المقارن. وتتمثل أدوات الدراسة في استمارة تحليل الأطر الخبرية، و المقابلة المتعمقة مع القائمين بالاتصال في مجال التعليم العالي بصحف الدر اسة. وتثمثل عينة الصحف التي ستخضع للار اسة في صحف أخبار اليوم و الوفد و الثروق، وسيتم إجر اء الدراسة خلال الفترة الزمنية من يناير 2015 وحتى يناير

- خطة مقدمة من الباحثة رضوى علاء محمود بعنوان "دور التربية الإعلامية

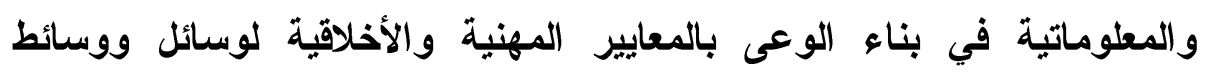
التواصل الاجتماعي" ، تحت إثراف أفئد ليلى عبد المجيد. لئل

تتمثل مشكلة الدر اسة في رصد وتوصيف وتحليل وتفسير دور التزبية الإعلامية و المعلوماتية في بناء الوعي بالمعايير المهنية و الأخلاقية لوسائل الإعلام ووسائط

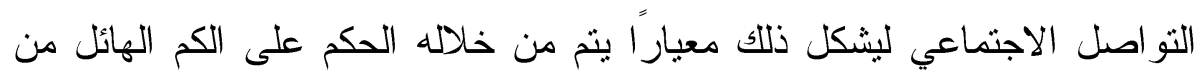
الرسائل الإعلامية المقدمة لهم من الوسائل الإعلامية المتعددة، وبالتالي الاستفادة

من مز ايا تلك الوسائل وتجنب التأثير ات السلبية لها.

وتستتد الدراسة إلى نظرية المسئولية الاجتماعية، وتتدرج الدراسة تحت نوعية الدر اسات الوصفية وتوظف منهج المسح من خلال مسح أساليب الممارسة للتعرف 
على كيفية تطبيق التزبية الإعلامية في المؤسسات الصحفية وتطبيقهم للأساليب

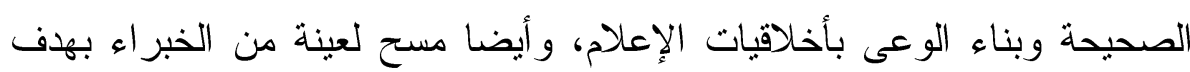
التعرف على دور التربية الإعلامية في بناء الوعى بالمعايير المهنية والأخلاقية

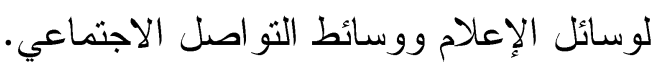

وتثمثل أدوات الدر اسة في استمارة الاستبيان، حيث سيتم تطبيق صحيفتين الأولى على عينة من الصحفيين و الثانية على عينة من خبر اء الإعلام وخبراء التربية، حيث ستقوم الباحثة على إجراء الار اسة على 100 مفردة من الإعلاميين و 300 مفردة من الخبراء في مجال الإعلام و التربية وخبراء تكنولوجيا الاتصال و المعلومات.

- خطة مقدمة من الباحث مؤمن أحمد السيد بعنوان "الضغوط المهنية والإدارية التي تواجه مراسلي الصحف المصرية في إقليم جنوب الصعيد" ، تحت إثر اف د. نيرمين الأزرق.

تستهف الدراسة رصد وتوصيف وتحليل ماهية الضغوط المهنية و الإدارية التي تؤثر على الأداء الإعلامي لمراسلي الصحف المصرية والتعرف عل رؤية المر اسلين لتأثثر هذه الضغوط على كفاءة أداؤهم المهني ومعرفة طريقة تعاملهم مع إلى هذه الظروف، وتحليل أهم المعوقات المجتمعية الأخرى التي من الممكن أن تؤثر على أداء المراسل الصحفي في إقليم جنوب الصعيد ومعرفة المقومات الأساسية التي لابد من تو افرها في المر اسل الصحفي لتحقيق الأهداف الإعلامية المنشودة. وتعتمد الدراسة في إطارها النظري على مدخل الرضا الوظيفي، وتتنمي إلى الدراسات الميدانية، وتعتمد على منهج المسح، وتثمثل أدوات جمع البيانات التي سيعتمد عليها الباحث في استمارة الاستبيان وجماعات النقاش المركزة مع مر اسلي الصحف المصرية عينة الدر اسة في إقليم جنوب الصعيد. 
وتثمثل عينة الدراسة الميدانية في المراسلين الصحفيين في إقليم جنوب الصعيد لصحف الأهرام و الأخبار و الجمهورية و المصري اليوم و الوفد و اليوم السابع و الوطن و الدستور و أخبار اليوم و الشروق و الفجر وصوت الأمة وروز اليوسف. 